\title{
CONTINUED STUDY OF THE TIME STABILITY OF A SMALL WATER CERENKOV DETECTOR
}

\author{
D. Strom, ${ }^{\mathrm{a}, \mathrm{c}}$ H. Glass, ${ }^{\mathrm{a}}$ H. Spinka, and M. Thomure ${ }^{\mathrm{a}}$ \\ ${ }^{a}$ Fermi National Accelerator Laboratory, Batavia, IL 60510 \\ b Argonne National Laboratory, Argonne, Il 60439 \\ c Augustana College, Rock Island, IL 61201
}

24 November, 1999

This note describes continued studies at Fermilab of the long term stability of a small water Cerenkov tank. Previous results are presented in Refs. [1,2] for studies between November, 1997 and October, 1998. The data given here continue these measurements through December, 1998, when the tank and electronics were moved to a different location, and then to November, 1999.

The water tank, bag liner, water, photomultiplier tube, and data acquisition software were unchanged for the additional measurements from June to November, 1999. However, some details of the geometry of the trigger counters relative to the tank and of the electronics may have differed. The setup for the 1999 results is described in this note.

The same analog-to-digital converter (ADC) was used for both time periods. Its pedestal was quite stable during the 1997-1998 measurements, but sizeable changes were observed in the more recent runs. As a result, dedicated pedestal runs were performed, and a number of additional tests were conducted.

\section{EXPERIMENTAL LAYOUT}

A schematic of the experimental setup is shown in Fig. 1. A pair of scintillation counters above and a second pair of scintillators below the tank were used to initiate the readout of the integrated signal from the photomultiplier in the water Cerenkov tank. The goal was to use cosmic ray muons that triggered all four scintillators and that passed approximately vertically through the water in the tank. These muons also passed through lead surrounding the lower pair of counters, so that their energy loss was approximately minimum ionizing. The path of the cosmic ray muons was chosen to be offset from the center of the tank so that most of them would not pass through the photomultiplier, where they might produce Cerenkov light in the glass face of the tube.

The submitted manuscript has been created by the University of Chicago as Operator of Argonne National Laboratory ("Argonne") under Contract No. W-31-109-ENG-38 with the US. Department of Energy The US Government retains for itself, and others acting on its behalf, a paid-up, nonexclusive. irrevocable worldwide license in saıd artıcle to reproduce, prepare derivative works, distribute copies to the public, and perform publicly and display publicly, by or on behalf of the Government. 


\section{DISCLAIMER}

This report was prepared as an account of work sponsored by an agency of the United States Government. Neither the United States Government nor any agency thereof, nor any of their employees, make any warranty, express or implied, or assumes any legal liability or responsibility for the accuracy, completeness, or usefulness of any information, apparatus, product, or process disclosed, or represents that its use would not infringe privately owned rights. Reference herein to any specific commercial product, process, or service by trade name, trademark, manufacturer, or otherwise does not necessarily constitute or imply its endorsement, recommendation, or favoring by the United States Government or any agency thereof. The views and opinions of authors expressed herein do not necessarily state or reflect those of the United States Government or any agency thereof. 


\section{DISCLAIMER}

Portions of this document may be illegible in electronic image products. Images are produced from the best available original documert. 


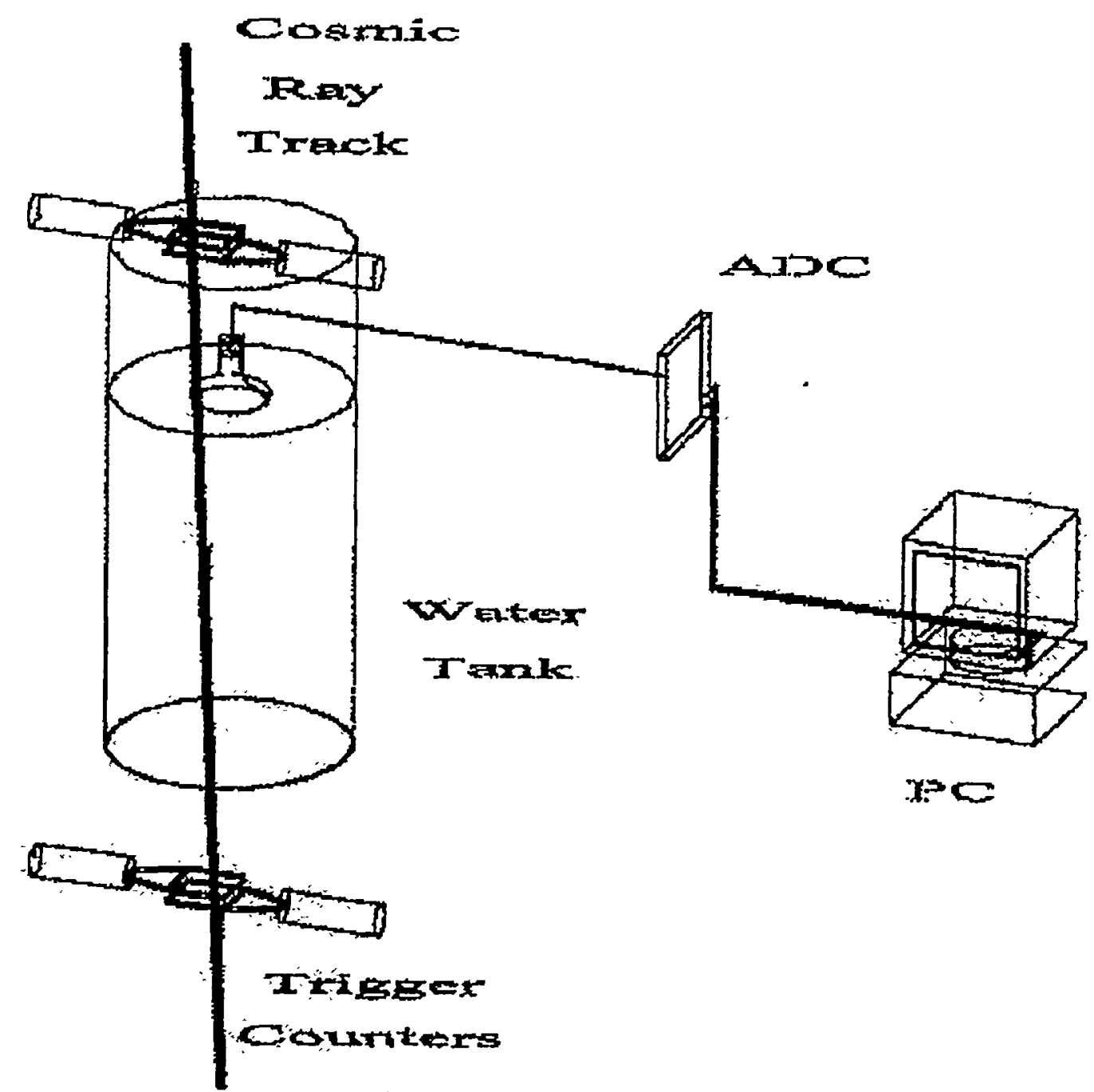

Figure 1. Schematic layout of the tests with the small water tank and trigger scintillators.

The tank, liner, water, and photomultiplier were moved together over a distance of several $\mathrm{km}$ in February, 1999. Except for any unintended consequences of the move, no other changes were made to this detector. Thus the 8 " photomultiplier (Hamamatsu R1408) and its resistive base were identical to the ones described in Refs. [1,2].

Similarly, the bag liner of polyethylene and Tyvek whose seams were thermally bonded, the 55 gallon steel drum/tank, and the water were not changed. The glass face of the photomultiplier was in contact with the water in a design similar to one from the large IMB proton decay experiment.

The trigger counters and cables may have differed from the earlier measurements, but such changes are expected to have quite minor impact on the types of triggered particles. Three of the four scintillators were 6" $\times 6$ " $\times$ ? " or $15.24 \times 15.24 \times 0.95 \mathrm{~cm}^{3}$ in size, and the fourth one was 8 " $\times 8$ " $\times 1 / 2$ " or $20.32 \times 20.32 \times 0.64 \mathrm{~cm}^{3}$. All were viewed by single 2" photomultipliers through trapezoidal-shaped lucite light guides. These light guides pointed in opposite directions within each pair of trigger counters, as shown in Fig. 1. 
Three counters were of identical construction to those used in the 1997-1998 experiments; some may actually have come from these earlier measurements.

The precise geometry for the 1999 runs is shown in Fig. 2 and probably changed somewhat from the 1997-1998 experiments. The lower pair of trigger scintillators were surrounded on two sides by 4 " $(10 \mathrm{~cm})$, and on the top by $2 "(5 \mathrm{~cm})$ of lead bricks. This was done to "harden" the spectrum of cosmic ray muons detected. The lead extended about 3" $(7.6 \mathrm{~cm})$ beyond the active area of the trigger counters, both towards and away from the photomultiplier tube.

The high voltages of the four trigger counters were set by performing "plateau curves," or recording coincidence rates in the upper or lower pair of counters as a function of the high voltage for one counter of the pair. However, these did not quite have the classical shape of plateau curves typically obtained with accelerator beams. It is not known whether plateau curves were also performed for the four trigger counters used during 1997-1998 runs, or whether the high voltages of any counters in common were the same. However, records of data collection indicate that the high voltage power supply for the trigger counters was changed in the middle of 1998 because of hardware problems. Voltage to all photomultipliers was found off in November, 1998 (near day 230) probably due to an interruption in the Fermilab AC power. During the 1999 runs, the voltages on the photomultipliers were checked several times with a voltage divider and DVM. No changes were observed from June to November, 1999. 


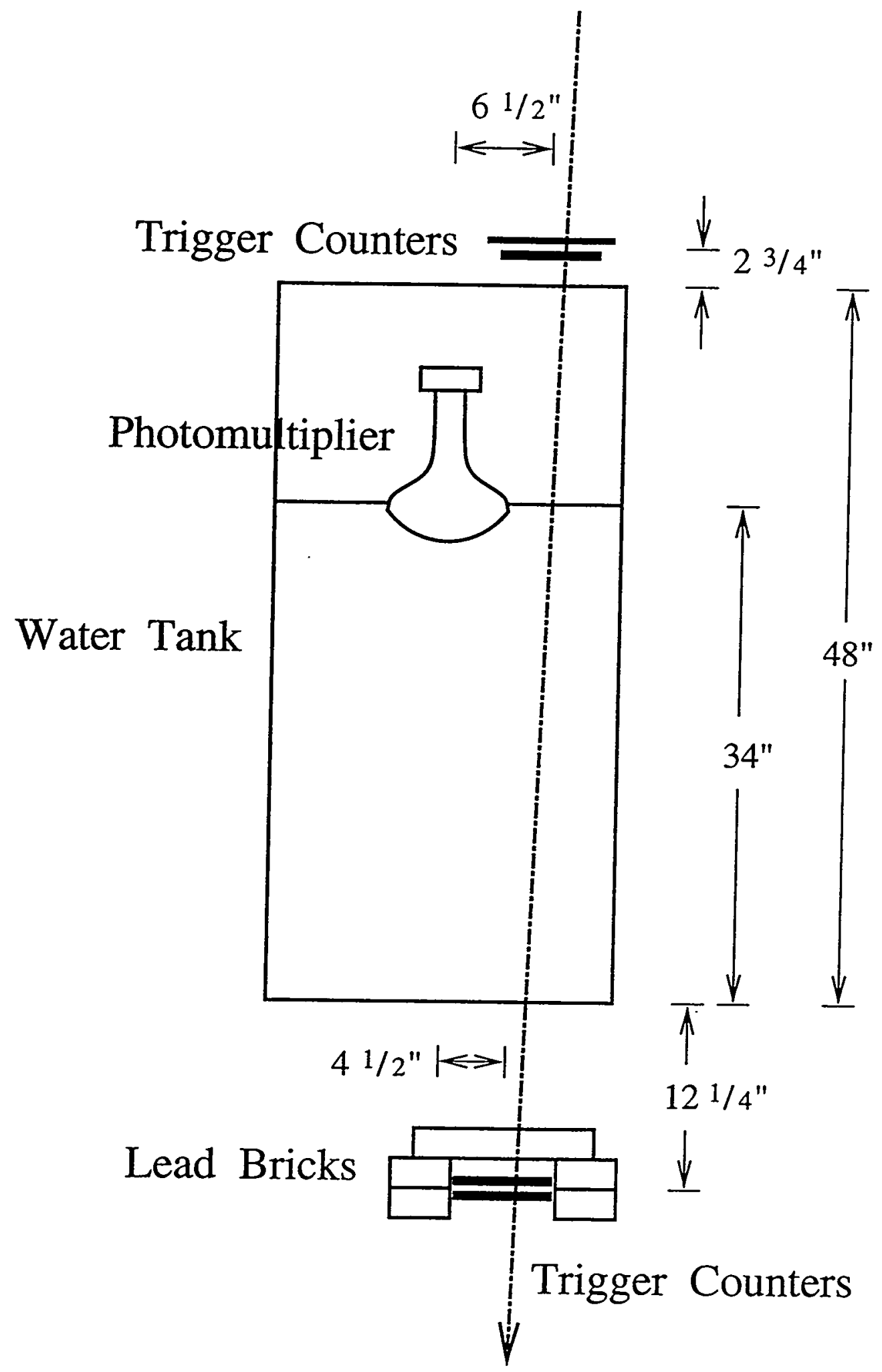

\section{Cosmic Ray Track}

Figure 2. Scale drawing of the water Cerenkov tank, photomultiplier tube, trigger counters, and lead bricks for the 1999 runs. 


\section{ELECTRONICS AND DATA ACQUISITION}

A schematic of the electronics is shown in Fig. 3. Most of the electronics modules and their settings were unchanged between the two run periods, though different cables were used in some cases. Similarly, the data acquisition software was unchanged.

Discr.

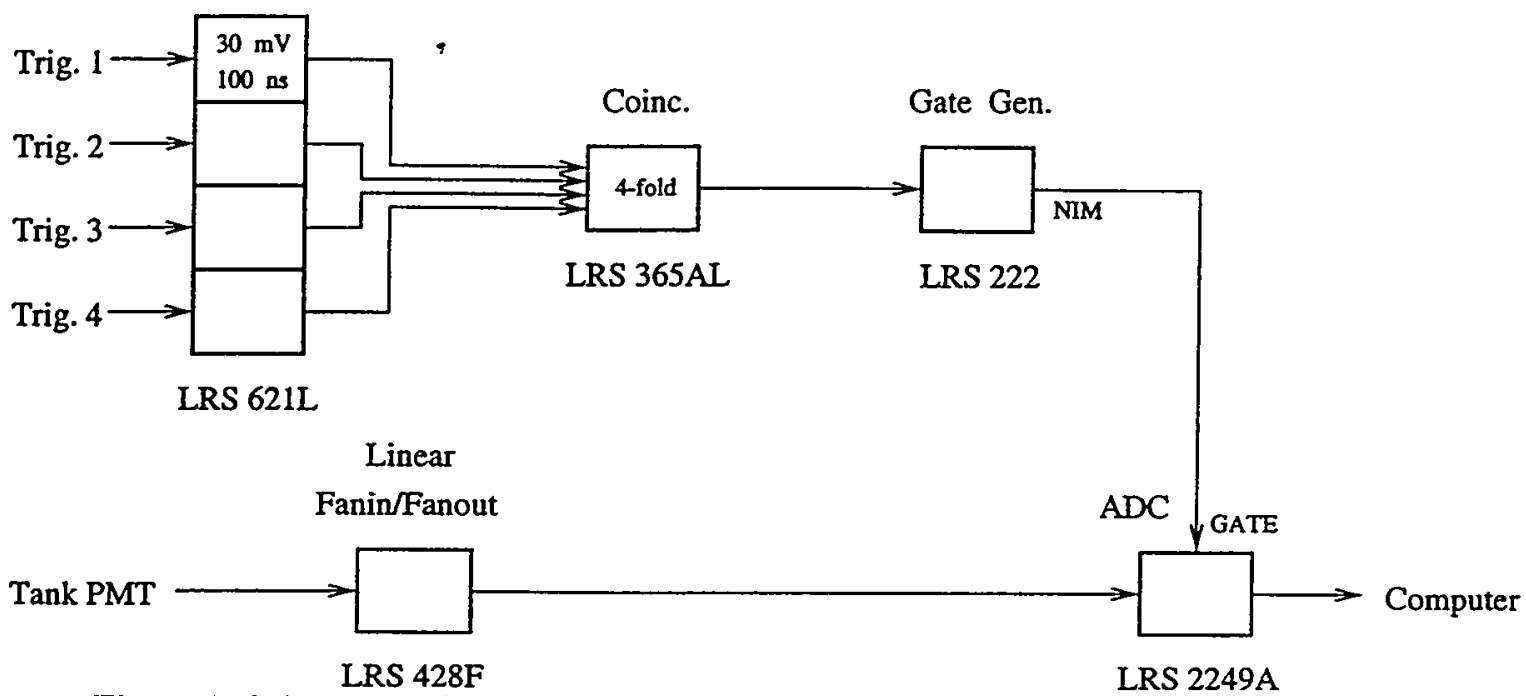

Figure 3. Schematic of the electronics for the small tank tests. All four channels of the discriminator had approximately the same threshold and width. The gate generator scale was $1 \mu \mathrm{sec}$, and the output width was adjusted to be about $250 \mathrm{nsec}$.

Negative high voltage for the trigger counters was supplied from a Fluke model 415B high voltage power supply and a Zener diode divider (homebuilt, type 11X 2562, from a LBL design). The positive high voltage for the photomultiplier inside the tank was also supplied from these same types of power supply and divider, and it was operated at a nominal voltage of $+1060 \mathrm{~V}$.

The signals from the trigger counter photomultipliers went to four channels of a LeCroy (LRS) model 621L NIM discriminator module, set to thresholds of $30 \mathrm{mV}$ and output widths of $100-110$ nsec. The outputs were required to form a 4-fold coincidence in a LRS 365AL module. The $50 \mathrm{nsec}$ wide coincidence signal was sent to a LRS 222 gate generator module that supplied the $250 \mathrm{nsec}$ gate to the $\mathrm{ADC}$ for the photomultiplier in the water tank. Typical 4-fold coincidence rates were 0.55 and 0.83 per minute during the 1997-1998 and the 1999 runs, respectively. The similarity of these rates suggests that the trigger selected a similar part of the steeply-falling cosmic ray energy spectrum.

The analog signal from the photomultiplier inside the water tank first went to a LRS $428 \mathrm{~F}$ linear fan-in/fan-out and then to a LRS 2249A Camac ADC after appropriate cable delay. The ADC was read out via a LRS 8901A GPIB interface module to a Dell model 310 personal computer running Windows 3.1. The data acquisition software (light2.c) is a $\mathrm{C}$ program that interfaces with the electronics using calls to the National Instruments GPIB library. The program sets up the ADC to generate a Look-At-Me (LAM) whenever it receives a trigger, and the $8901 \mathrm{~A}$ to generate a service request (SRQ) when it sees a 
LAM. The program repeatedly polls the 8901A until it sees an SRQ. It then reads out the raw $A D C$ values and re-arms the electronics for the next trigger. The $A D C$ value was converted to integrated current using the nominal value of 0.25 picoCoulombs $(\mathrm{pC})$ per channel for the $A D C$, and a fixed pedestal subtracted before the result was stored in an ascii file. The time of the event from the internal computer clock was also recorded in the file.

A typical spectrum from a 92 hr run in July 1999 is shown in Fig. 4 in both a linear and semi-logarithmic scale. The small peak near $30 \mathrm{pC}$ corresponds to the pedestal value. This was confirmed by the results of dedicated pedestal runs taken close in time to the cosmic ray data using an ADC gate that occurred at a random time. The pedestal events are present in the cosmic ray data due to accidental coincidences. For example, two cosmic ray muons could occur close in time - one hitting the upper pair and the other striking the lower pair of trigger counters, but neither passing through the water tank. The rate of pedestal events in a normal cosmic ray run is roughly 0.6 per hour. Finally, the ADC saturated near $260 \mathrm{pC}$, leading to the excess of events observed in Fig. 4. 

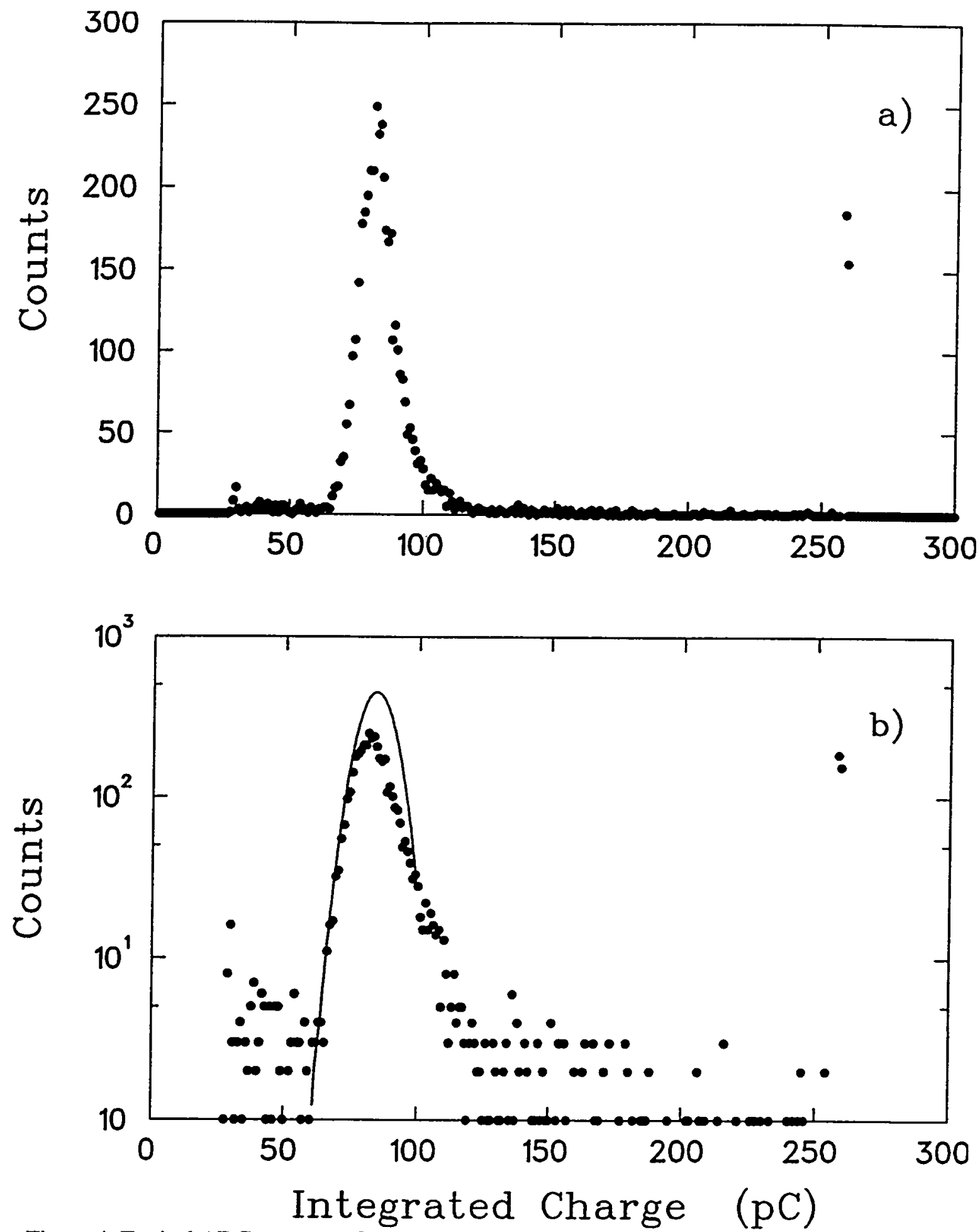

Figure 4. Typical ADC spectrum from the small tank photomultiplier in a) linear and b) semilogarithmic scales. The pedestal is near $30 \mathrm{pC}$, saturation occurs near $260 \mathrm{pC}$, and the run number was tst2019. Results of a Gaussian fit to the peak from the EXCEL program is also shown; for most runs the fit is better than the one shown here. 


\section{DATA ANALYSIS}

The raw data were analyzed in two ways; one using commercial software (Microsoft EXCEL), and the other using code written by one of the authors. The results from the two methods are quite similar, and differences allow estimates of systematic errors. They also permit checks on estimated statistical errors from the commercial software.

For the first type of analysis, the raw data were copied onto a computer cluster at Fermilab. The files were then read by the EXCEL spreadsheet software, and sorted into a histogram with bin width $2 \mathrm{pC}$ using a macro. The pedestal was estimated as described below, and a Gaussian was fit to the events near the peak in the spectrum (about $80 \mathrm{pC}$ in Fig. 4). A second macro was written to perform some of these calculations; details are included in Ref. [3].

The pedestal for both cosmic ray and pedestal runs was estimated in the same way. The mean $\left.(<\mathrm{x}\rangle_{\mathrm{P}}\right)$ and standard deviation $\left(\sigma_{\mathrm{P}}\right)$ were computed for all events in the pedestal region. This region was chosen to be $10 \mathrm{pC}$ wide beginning with the lowest charge recorded in an event near the pedestal. For example, for the run in Fig. 4 (tst2019), the pedestal region included events between 28 and $38 \mathrm{pC}$, and the calculations gave $\angle \mathrm{x}>\mathrm{p}=$ $32.2 \mathrm{pC}$ and $\sigma_{\mathrm{P}}=2.8 \mathrm{pC}$. The uncertainty on the pedestal mean was

$$
\sigma_{\infty>}=\sigma_{p} /(n-1)^{1 / 2},
$$

where $\mathrm{n}$ is the total number of events in the pedestal region. Table 1 contains a list of the pedestals and uncertainties, dates, and run numbers for all "useful runs" between March 1998 and December 1999, including dedicated pedestal runs; data from before March, 1998 were not available. Figure 5 gives a plot of the pedestal values as a function of time during the 1999 runs; the pedestal seemed to be close to zero and nearly constant during the 1998 runs analyzed. Considerable variation is observed in the 1999 pedestal values.

The fit to the peak in the cosmic ray spectrum was performed with EXCEL software as well. For most runs, the region in the spectrum from $60-100 \mathrm{pC}$, approximately centered on the peak, was fit with a Gaussian in order to estimate the peak position $(<x>)$ and width $(\sigma)$. (For runs where the peak occurred at a value considerably different from $80 \mathrm{pC}$, other limits were used.) The fits were not very good, since the spectrum shape is clearly asymmetric and non-Gaussian, as can be seen in Fig. 4. The results are given in Table 2, along with an estimated error in $\langle x\rangle$. This uncertainty was taken to be

$$
\delta(<\mathrm{x}>) \sim \sigma / \mathrm{N}^{1 / 2},
$$

where $\mathrm{N}$ is the total number of events from the Gaussian fit. The raw peak positions, $<x>$, are plotted as a function of time during the 1999 runs in Fig. 6 . The peaks corrected for the pedestals $\left(\langle y\rangle=\langle x\rangle-\langle x\rangle_{p}\right)$ are given in Fig. 7. The raw peak positions show considerably larger variations than the values corrected for pedestals. 
The number of photoelectrons corresponding to the peak in the ADC spectrum was computed from the relation

$$
\# \text { p.e. }=1.5 /(\sigma /<y>)^{2},
$$

taken from Ref. [4]. Assuming negligible errors on the pedestal determination, the uncertainty in this estimate is

$$
\delta(\# \text { p.e. })=(\# \text { p.e. })\left(2 / \mathrm{N}^{1 / 2}\right)\left[\mathrm{N} /(\mathrm{N}-1)+\sigma^{2} /\langle\mathrm{y}\rangle^{2}\right]^{1 / 2} \text {, }
$$

which has the expected dependence on $\mathrm{N}^{-1 / 2}$, for $\mathrm{N}$ the total number of events in the ADC spectrum peak. In addition, the effect of the pedestal uncertainty can be added in quadrature with the error estimate on the number of photoelectrons above, though this contribution was found to be small. The results for the number of photoelectrons are given in Fig. 8 with uncertainties shown for the case with the pedestal error included.

The alternate method for determining the peak and width of the ADC spectrum involved an iterative procedure. In the first step, the mean $\left(\left\langle x_{1}\right\rangle\right)$ of the events with integrated charge between 60 and $100 \mathrm{pC}$ was computed. (Again, different limits were used when the peak occurred far from $80 \mathrm{pC}$.) For the second step, events in the range

$$
\left\langle\mathrm{x}_{1}\right\rangle-0.4\left(\left\langle\mathrm{x}_{1}\right\rangle-\left\langle\mathrm{x}_{\mathrm{P}}\right)<\text { Charge }<\left\langle\mathrm{x}_{1}\right\rangle+0.4\left(\left\langle\mathrm{x}_{1}\right\rangle-\langle\mathrm{x}\rangle_{\mathrm{P}}\right)\right.
$$

were used to compute the mean, $\left\langle\mathrm{x}_{2}\right\rangle$, and the standard deviation, $\sigma_{2}$. For the third step, $\left\langle\mathrm{x}_{2}\right\rangle$ replaced $\left\langle\mathrm{x}_{1}\right\rangle$ in the limits above, and the calculations yielded $\left\langle\mathrm{x}_{3}\right\rangle$ and $\sigma_{3}$. This procedure was continued until the results converged. Such an iteration partially compensated for variation in the gain of the system. It would work best if the shape of the spectrum was unchanged except for the overall gain. The mean and standard deviation of the peak when the iteration converged are also given in Table 2 for a sampling of runs. Generally, the peak position was $1-2 \mathrm{pC}$ less and the width was somewhat larger than the Gaussian fit using the EXCEL software. In addition, the number of events was usually slightly larger, mostly from the events on the high pulse height tail of the peak distribution. 


\section{Pedestal}

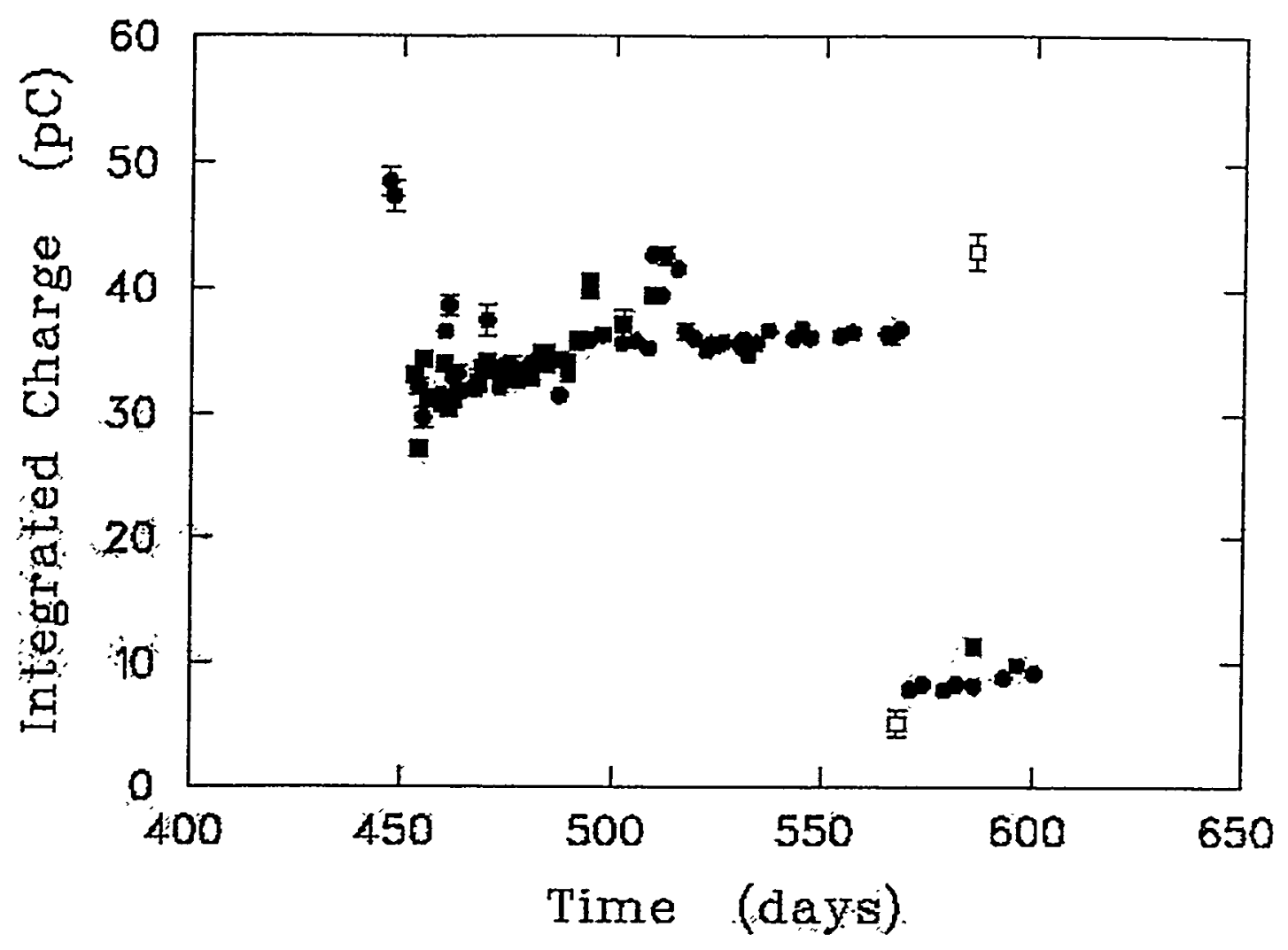

Figure 5. Variation of the pedestal in the ADC spectra as a function of time for the 1999

runs. The two runs denoted by open squares are test runs, as noted in the text. The solid squares are from dedicated pedestal runs and the solid circles from normal cosmic ray runs. 


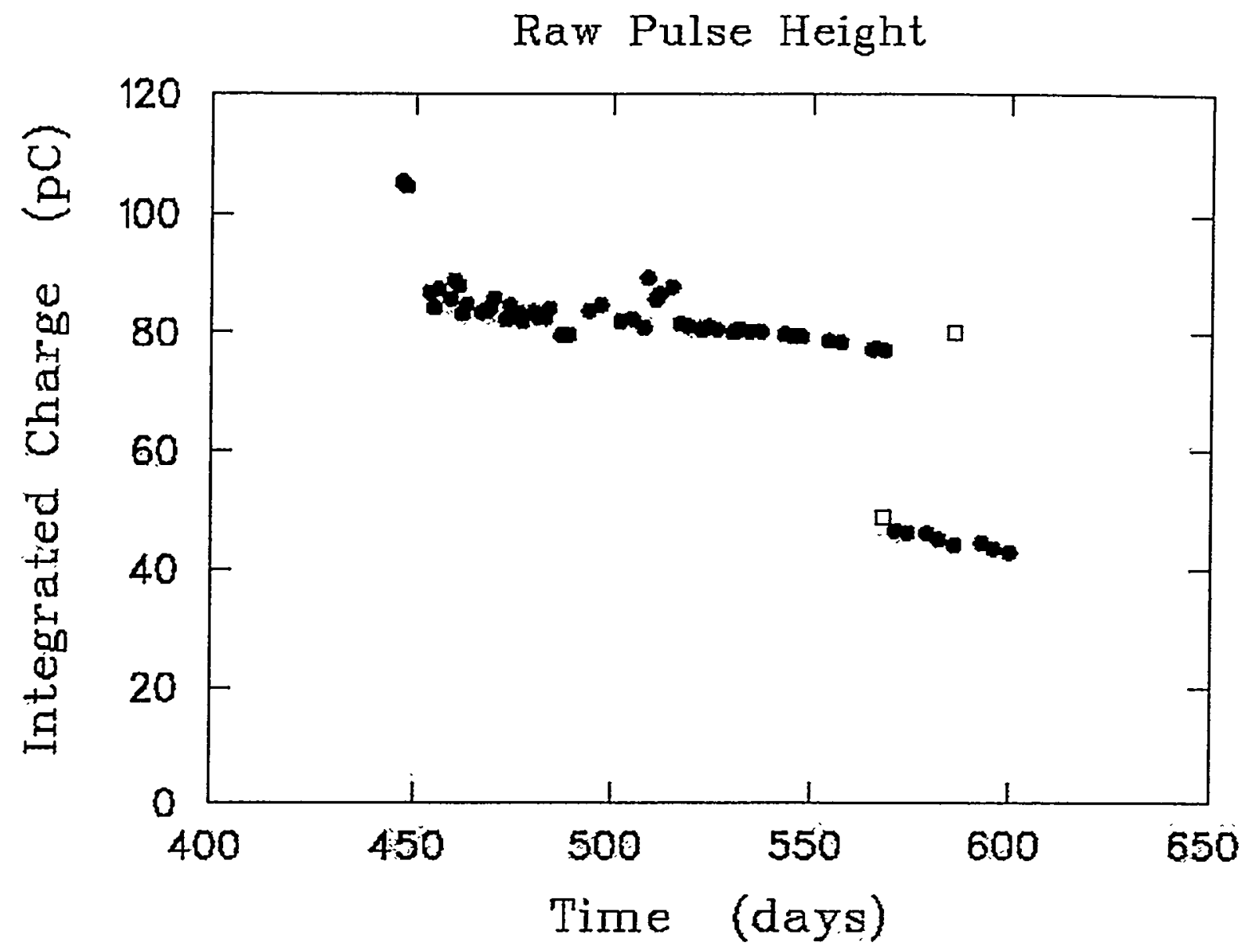

Figure 6. Plot of the raw peaks in the ADC spectra as a function of time for the 1999 runs. The peak positions were estimated from the Gaussian fits using EXCEL software. The computed uncertainties are smaller than the points. The results denoted by open squares are from test runs, as noted in the text. 


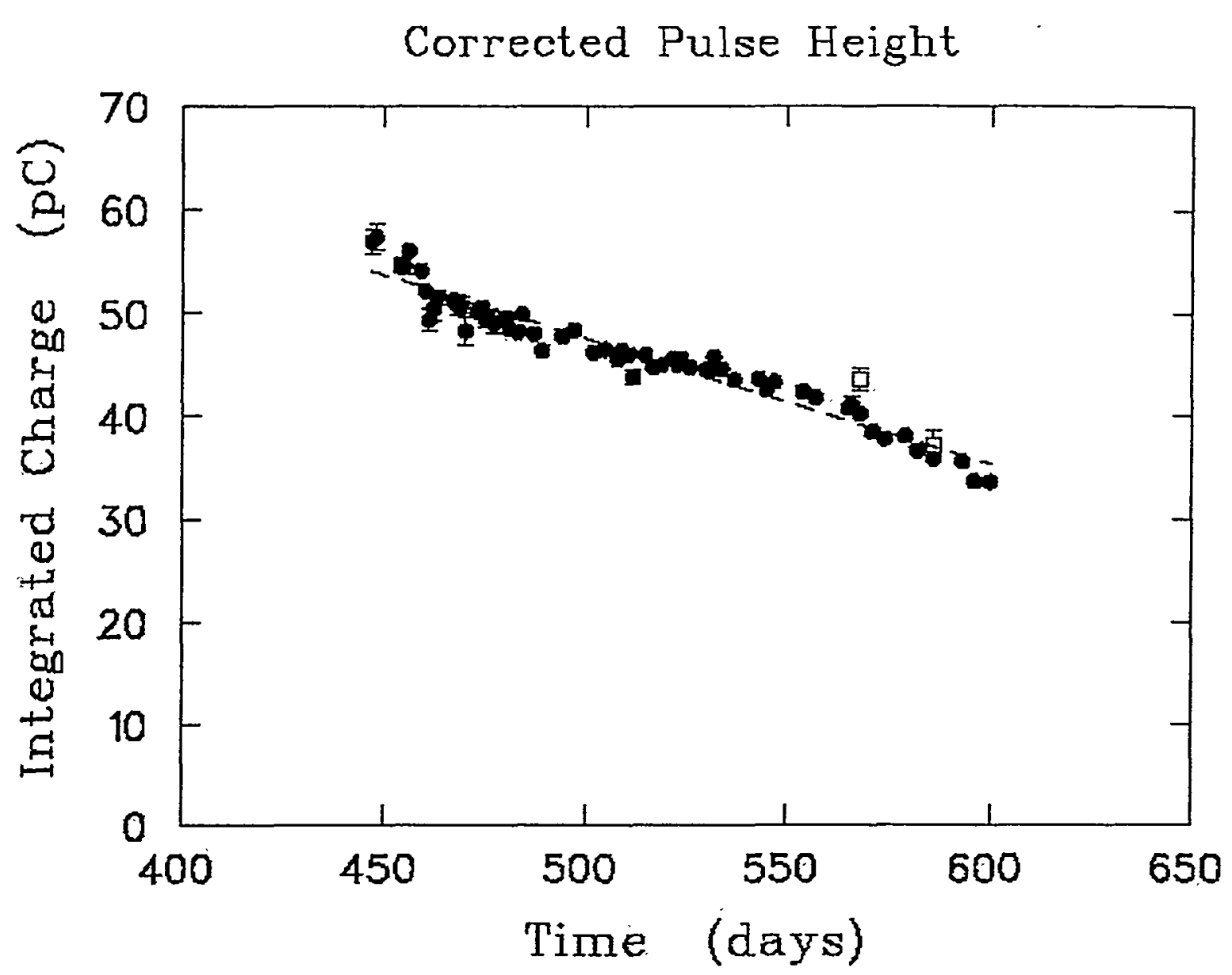

Figure 7. Plot of the peak positions in the ADC spectra, corrected by the pedestal values, as a function of time for the 1999 runs. The computed uncertainties are generally smaller than the points. The results denoted by open squares are from test runs, as noted in the text. The dashed curve is the straight line fit to the points.

\section{RESULTS}

Considerable variation is observed in the pedestal values with time shown in Figs. 5 and 9. Several discontinuities are apparent. The one in October, 1999 near day 570 occurred at the time of a test, as described below. There was also a jump in the pedestal at some time during early 1999, when no data were being collected and the move of the apparatus to the new location took place. Other discontinuities did not correspond to any hardware change. A gradual increase in the pedestal values with time until the sharp drop near day 570 is also apparent. In any case, such variation was not observed during the 1997 - 1998 measurements, before the move. It was also observed that the pedestal run and the cosmic ray run pedestals are generally in good agreement (these runs are mixed together in Figs. 5 and 9). 
Similarly, Fig. 6 with the raw peak values shows considerable variations, also with discontinuities at the same times as the pedestal results. A gradual decrease in these peak values is also observed until the sharp drop near day 570 .

By contrast, the peaks corrected for pedestals exhibit a smooth, decreasing behavior with time as can be seen in Fig. 7. On this basis, it is expected that the pedestal determination and subtraction have been done correctly and are necessary for these data. This decrease is consistent with neither linear nor exponential behavior. For example, a straight line fit to these data (shown in Fig. 7) gives

$$
\text { Charge }=(-0.1220 \pm 0.0013) * \text { Time (days) }+(108.61 \pm 0.67),
$$

with a $?^{2} /$ d.f. $=463.2 / 59=7.85$. The average drop from 16 June, 1999 (day 447) to 16 November, 1999 corresponds to approximately $80 \%$ / year if the peak values were to continue to fall linearly.

Two short test runs were conducted (tst2094 on day 568 and tst2101 on day 586) to check for problems with the electronics. In the first one, the LRS 2249A ADC was physically replaced with another, identical ADC. The original ADC was then put back for run tst2095 and all following data. A significant change in the pedestal occurred (Fig. 5), but the peak corrected for pedestal was close to that for other nearby runs (Fig. 7). However, the pedestal also changed for the original $A D C$ when it was put back into the CAMAC crate!

The second test had a change in the channel of the LRS 428F linear fan-out. Again the pedestal changed but the peak corrected for pedestal did not. It was concluded from these two tests and the HV measurements that the drop in pulse height from the photomultiplier in the small tank was not due to electronics problems (photomultiplier HV, linear fan-out, or ADC). Furthermore, the tank is located inside a large building. The temperature was occasionally monitored from June to November, 1999 and varied from 73 to $76^{\circ} \mathrm{F}$, but not correlated with the season. This small temperature variation is not expected to be the cause of the sizeable drop in integrated charge either.

One further test was performed. If the gain of the R1408 photomultiplier was constant, but the amount of light reaching the tube was decreasing, then it would be expected that the calculated number of photoelectrons and the integrated charge would decrease together. In particular, the straight line fit from Fig. 7 should be roughly proportional to the number of photoelectrons. The scaled straight line fit is shown in Fig. 8 with a scale factor of $(2.0$ photoelectrons / pC). There is reasonable agreement with this line, but not with a constant value. This test reinforces the case for a drop in the amount of light reaching the photomultiplier.

On 16 November, 1999 it was decided to look into the small tank. No standing water was observed on top of the bag, and the photomultiplier base did not appear corroded. The water appeared clear and the photomultiplier glass had no obvious deposits present. The inside of the tyvek bag did not feel "slimy", and exhibited no apparent discoloration. 
Unfortunately, the water was contaminated during the removal of the photomultiplier, so that the test with this small tank had to be concluded. (A chemical analysis of the water would have been meaningless.)

\section{ACKNOWLEDGEMENTS}

We wish to thank our Fermilab colleagues - Paul Mantsch, Peter Mazur, Carlos Hojvat, Lou Voyvodic, Rich Andrews, and Larry Coulson, and visitors Andrej Filipcic and Bai Xinhua - for their assistance with these studies. This work was supported in part by Fermilab, under contract with the U.S. Department of Energy, Division of High Energy Physics, and by an Argonne National Laboratory - University of Chicago collaborative grant. Authors Derek Stron and Mick Thomure were supported under a summer students program at Fermilab.

\section{REFERENCES}

[1] Xinhua, Bai, "Test of the Aging Effect of a Bag Liner with a Small Water Cerenkov Detector," Pierre Auger Project Technical Note GAP-98-010 (1998).

[2] Filipcic, A., "The Time Stability of a Small Water Cerenkov Detector," Pierre Auger Project Technical Note GAP-98-*** (1998).

[3] Strom, D., "Stability of Water in a Small Cerenkov Detector," Fermilab summer student report (1999). The uncertainties on the fitted peaks are too small by $2^{1 / 4}$ in this report because of an error in the EXCEL analysis. This error was located by the comparison of these data with the alternate analysis results.

[4] Ravignani, D., P. Bauleo, A. Etchegoyen, A.M.J. Ferrero, A. Filevich, C.K. Guerard, F. Hasenbalg, and J. Rodriguez Martino, "Calculation of the Number of Photoelectrons with the Water Cerenkov Detector Model," Pierre Auger Project Technical Note GAP-97-024 (1997). 


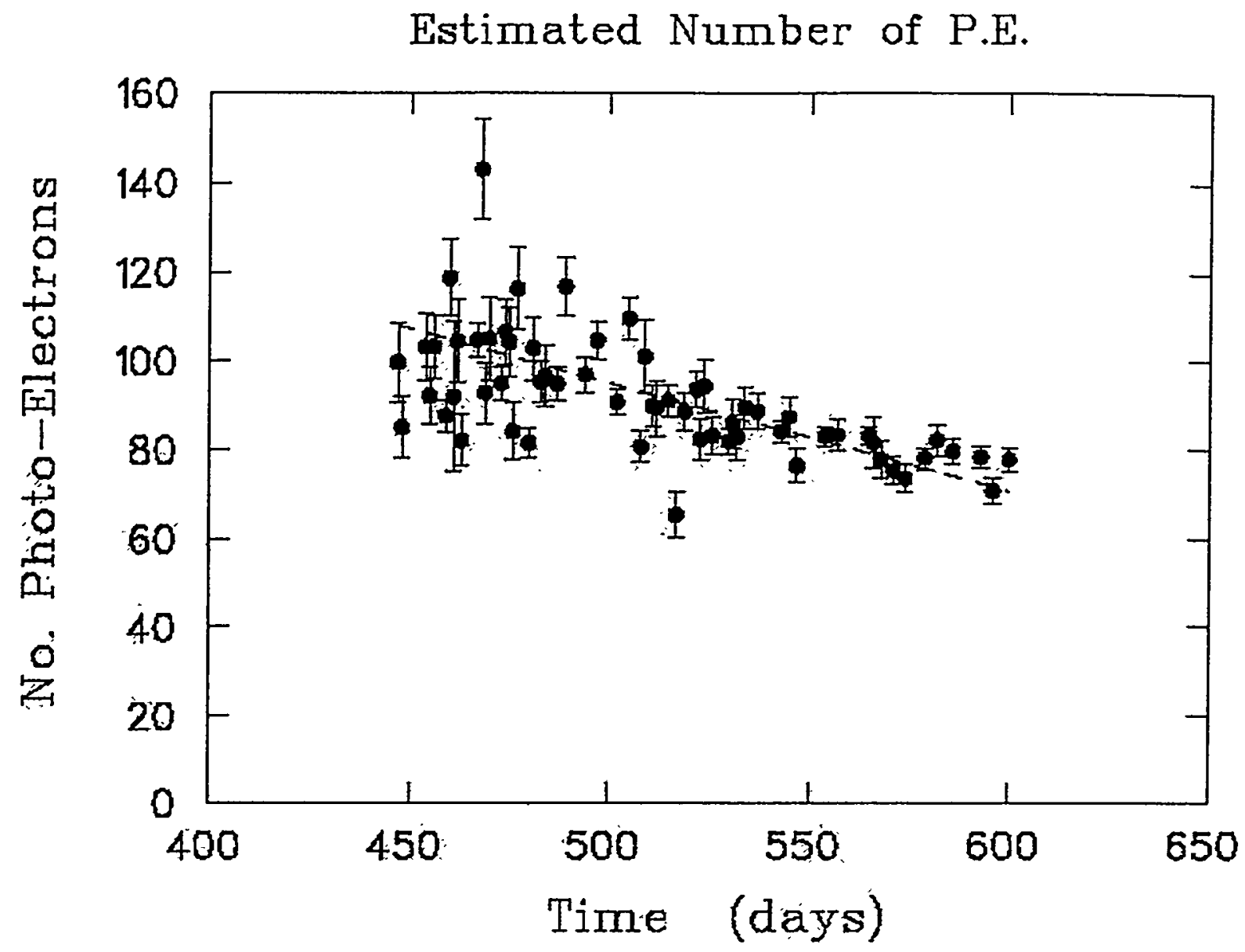

Figure 8. Variation of the derived number of photoelectrons as a function of time for the June, 1999 to November, 1999 runs. The errors include the contribution from the pedestal uncertainty. The dashed curve shows the approximate expected behavior from the straight line fit to the data in Fig. 7. 


\section{Pedestal}

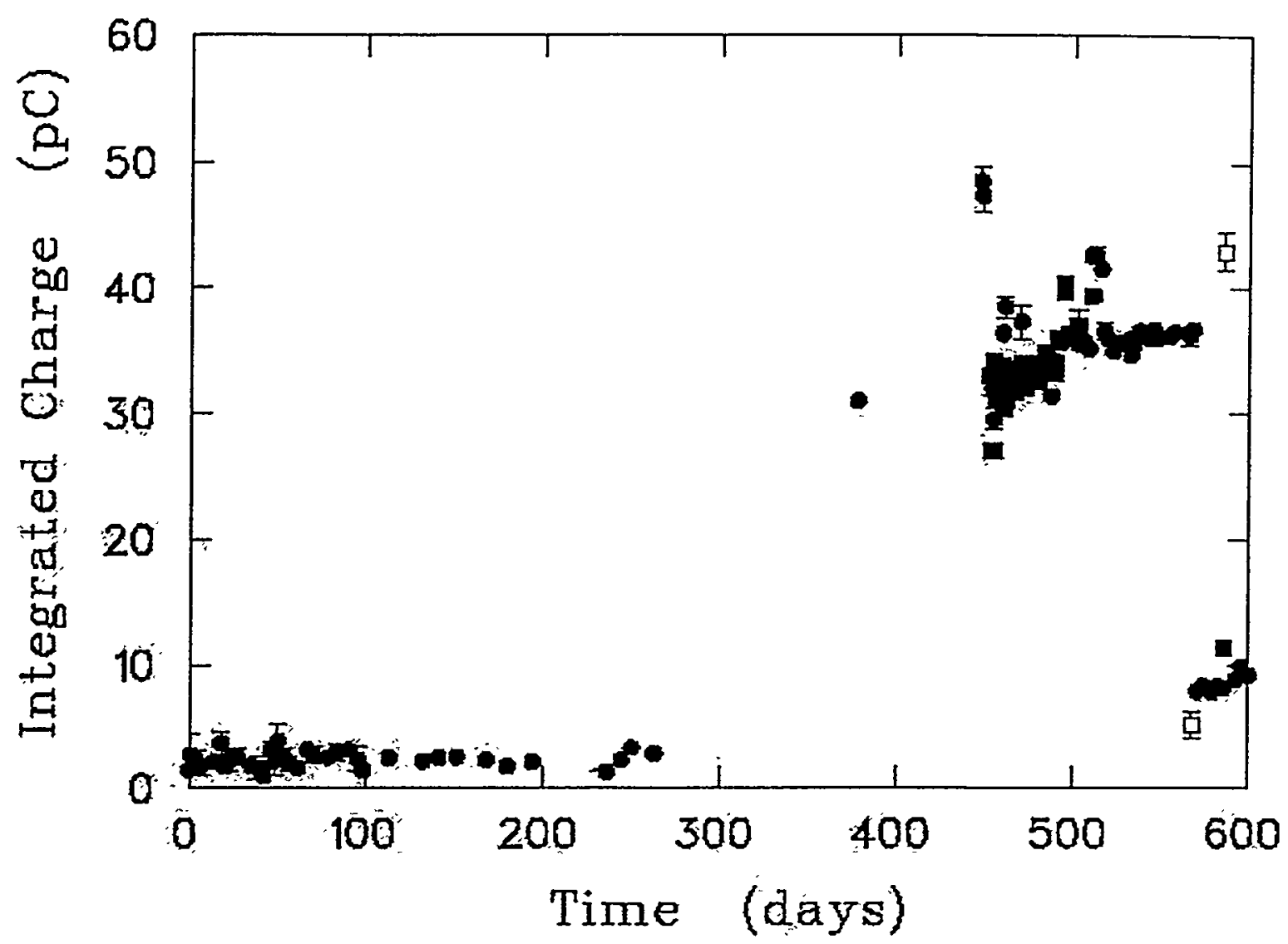

Figure 9. Variation of the pedestal in the ADC spectra as a function of time for the runs from March, 1998 until November, 1999. The solid squares are from dedicated pedestal runs and the solid circles from normal cosmic ray runs. 
Corrected Pulse Height

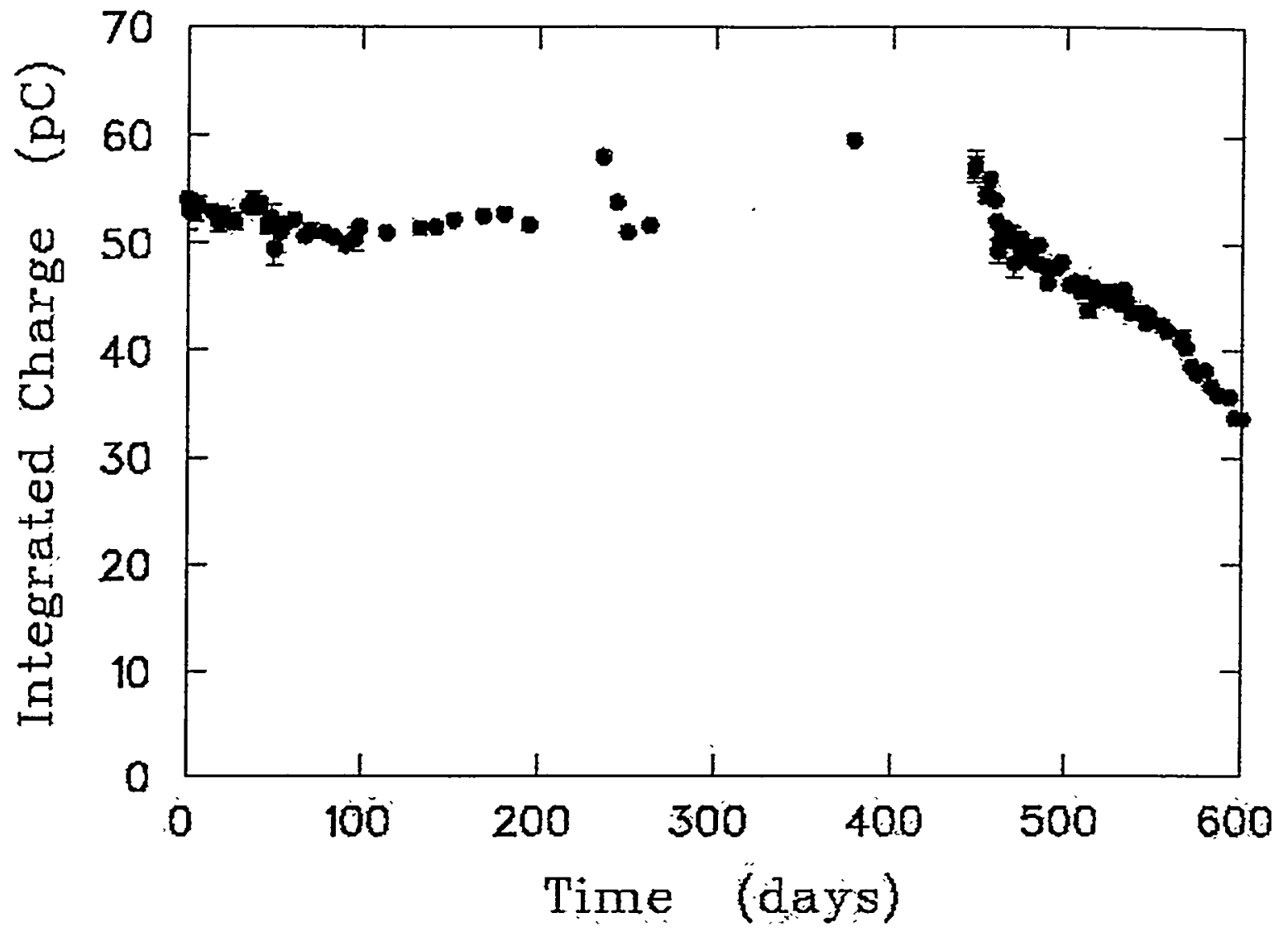

Figure 10. Plot of the peak positions corrected for pedestals for the March, 1998 to November, 1999 runs. 


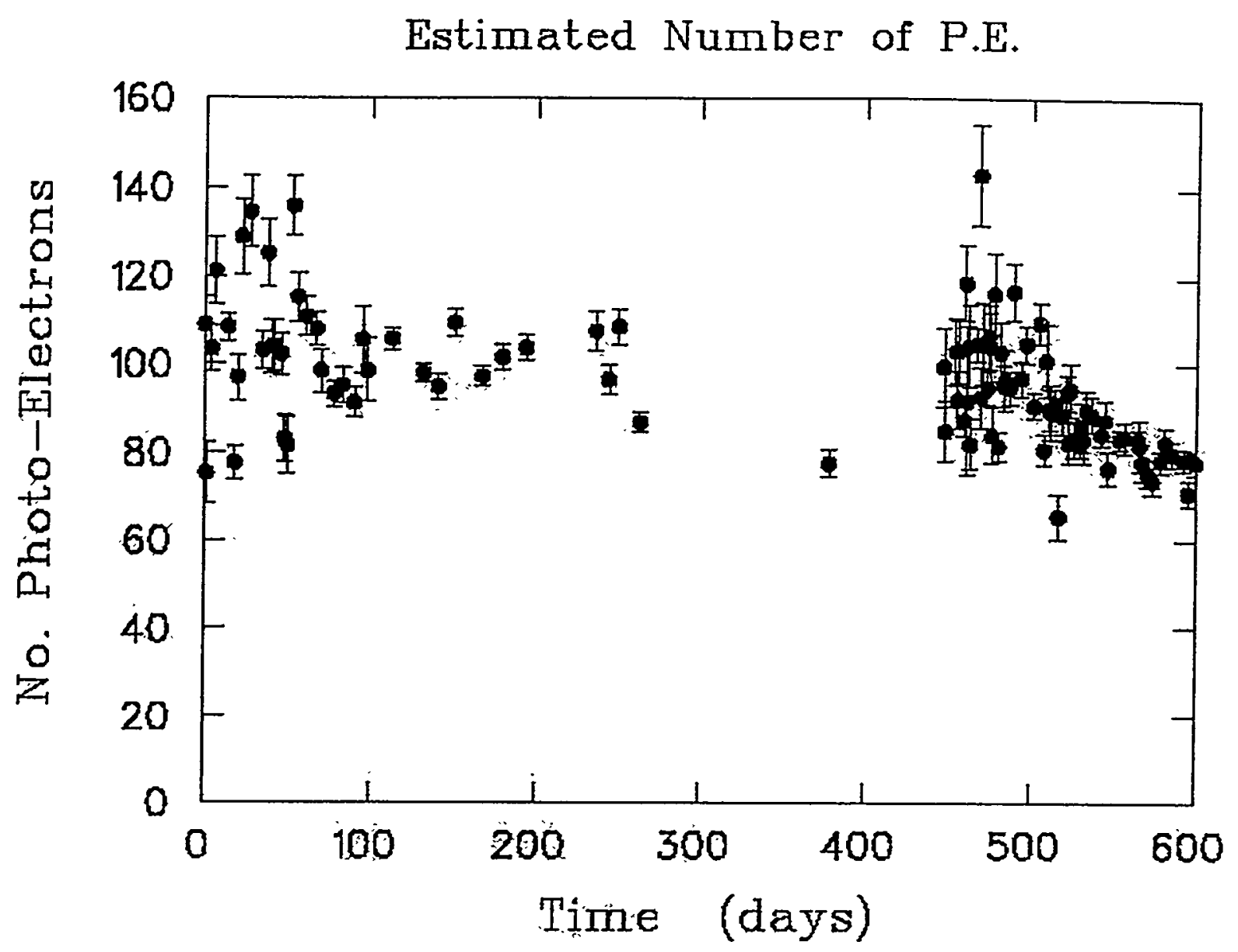

Figure 11. Plot of the computed number of photoelectrons as a function of time for the June to November, 1999 runs. The errors include the contribution from the pedestal uncertainty. 
GAP2000-001

Table 1.

Pedestals for data runs with the small tank between March, 1998 and November, 1999. The date quoted is the day the run ended. The error is the uncertainty on the mean pedestal. The number of events in the pedestal region is also shown. The pedestal and error are in units of $\mathrm{pC}$.

\begin{tabular}{lrrrrr} 
Run Number & Date & Day & Pedestal & Error & Events \\
& & & & & \\
tst1942 & $03 / 26 / 98$ & 0 & 1.45 & 0.42 & 10 \\
tst1943 & $03 / 27 / 98$ & 1 & 2.64 & 1.66 & 6 \\
tst1944 & $03 / 30 / 98$ & 4 & 2.32 & 0.73 & 20 \\
tst1945 & $04 / 01 / 98$ & 6 & 1.67 & 0.70 & 15 \\
tst1946 & $04 / 09 / 98$ & 14 & 2.11 & 0.37 & 58 \\
tst1947 & $04 / 13 / 98$ & 18 & 3.62 & 0.88 & 15 \\
tst1948 & $04 / 15 / 98$ & 20 & 1.72 & 0.59 & 15 \\
tst1949 & $04 / 17 / 98$ & 22 & 2.21 & 0.87 & 11 \\
tst1952 & $04 / 22 / 98$ & 27 & 2.53 & 0.72 & 18 \\
tst1954 & $04 / 30 / 98$ & 35 & 1.78 & 0.59 & 17 \\
tst1956 & $05 / 03 / 98$ & 38 & 1.64 & 0.89 & 11 \\
tst1957 & $05 / 05 / 98$ & 40 & 1.41 & 0.67 & 8 \\
tst1958 & $05 / 07 / 98$ & 42 & 0.90 & 0.60 & 10 \\
tst1959 & $05 / 11 / 98$ & 46 & 2.99 & 0.75 & 22 \\
tst1960 & $05 / 13 / 98$ & 48 & 2.14 & 1.12 & 9 \\
tst1961 & $05 / 15 / 98$ & 50 & 3.78 & 1.46 & 7 \\
tst1962 & $05 / 18 / 98$ & 53 & 2.55 & 0.66 & 24 \\
tst1963 & $05 / 21 / 98$ & 56 & 1.93 & 0.61 & 18 \\
tst1964 & $05 / 26 / 98$ & 61 & 1.64 & 0.51 & 33 \\
tst1965 & $06 / 01 / 98$ & 67 & 3.06 & 0.50 & 51 \\
tst1966 & $06 / 04 / 98$ & 70 & 2.66 & 0.72 & 19 \\
tst1967 & $06 / 12 / 98$ & 78 & 2.53 & 0.41 & 56 \\
tst1968 & $06 / 17 / 98$ & 83 & 2.82 & 0.65 & 29 \\
tst1969 & $06 / 24 / 98$ & 90 & 3.07 & 0.55 & 42 \\
tst1970 & $06 / 29 / 98$ & 95 & 2.34 & 1.03 & 11 \\
tst1972 & $07 / 02 / 98$ & 98 & 1.45 & 0.40 & 60 \\
tst1973 & $07 / 17 / 98$ & 113 & 2.44 & 0.31 & 90 \\
tst1975 & $08 / 05 / 98$ & 132 & 2.19 & 0.31 & 102 \\
tst1976 & $08 / 14 / 98$ & 141 & 2.45 & 0.39 & 67 \\
tst1977 & $08 / 24 / 98$ & 151 & 2.53 & 0.40 & 56 \\
tst1978 & $09 / 10 / 98$ & 168 & 2.27 & 0.31 & 59 \\
tst1979 & $09 / 22 / 98$ & 180 & 1.75 & 0.37 & 21 \\
tst1980 & $10 / 06 / 98$ & 194 & 2.09 & 0.41 & 39 \\
tst1984 & $11 / 17 / 98$ & 236 & 1.30 & 0.47 & 35 \\
tst1985 & $11 / 25 / 98$ & 244 & 2.22 & 0.48 & \\
tst1986 & $12 / 01 / 98$ & 250 & 3.21 & 0.47 & \\
tst1987 & $12 / 14 / 98$ & 263 & 2.77 & 0.40 & \\
& & & & & \\
\hline
\end{tabular}

The tank was moved after this run.

$\begin{array}{llllll}\text { tst1991 } & 06 / 16 / 99 & 447 & 48.46 & 1.17 & 13 \\ \text { tst1993 } & 06 / 17 / 99 & 448 & 47.36 & 1.24 & 11\end{array}$




\begin{tabular}{|c|c|c|c|c|c|}
\hline Run Number & Date & Day & Pedestal & Error & Events \\
\hline tst2001 & $06 / 22 / 99$ & 453 & 33.05 & 0.28 & \\
\hline tst2002 & $06 / 23 / 99$ & 454 & 32.11 & 0.67 & \\
\hline tst2003 & $06 / 23 / 99$ & 454 & 27.10 & 0.11 & \\
\hline tst2004 & $06 / 24 / 99$ & 455 & 29.63 & 0.79 & \\
\hline tst2005 & $06 / 24 / 99$ & 455 & 34.27 & 0.38 & \\
\hline tst2006 & $06 / 25 / 99$ & 456 & 31.28 & 0.41 & \\
\hline tst2007 & 06/25/99 & 456 & 31.29 & 0.18 & \\
\hline tst2008 & $06 / 28 / 99$ & 459 & 31.51 & 0.35 & \\
\hline tst2009 & 06/28/99 & 459 & 30.63 & 0.12 & \\
\hline tst2010 & $06 / 29 / 99$ & 460 & 36.54 & 0.57 & 2 \\
\hline tst2011 & $06 / 29 / 99$ & 460 & 33.99 & 0.044 & 14 \\
\hline tst2013 & $06 / 30 / 99$ & 461 & 38.59 & 0.85 & \\
\hline tst2014 & $06 / 30 / 99$ & 461 & 30.38 & 0.17 & \\
\hline tst2015 & 07/01/99 & 462 & 32.83 & 1.02 & 1 \\
\hline tst2016 & $07 / 01 / 99$ & 462 & 31.09 & 0.079 & 5 \\
\hline tst2017 & $07 / 02 / 99$ & 463 & 33.18 & 0.67 & \\
\hline tst2018 & $07 / 02 / 99$ & 463 & 31.71 & 0.072 & 6 \\
\hline tst2019 & $07 / 06 / 99$ & 467 & 32.22 & 0.43 & \\
\hline tst2020 & 07/06/99 & 467 & 31.85 & 0.065 & 0 \\
\hline tst2021 & $07 / 07 / 99$ & 468 & 32.67 & 0.87 & t \\
\hline tst2022 & 07/07/99 & 468 & 32.47 & 0.064 & \\
\hline tst2024 & $07 / 08 / 99$ & 469 & 33.46 & 0.73 & 比 \\
\hline tst2025 & 07/08/99 & 469 & 33.47 & 0.14 & 6 \\
\hline tst2026 & $07 / 09 / 99$ & 470 & 37.44 & 1.32 & \\
\hline tst2027 & $07 / 09 / 99$ & 470 & 34.12 & 0.056 & 7 \\
\hline tst2028 & 07/12/99 & 473 & 32.05 & 0.38 & 6 \\
\hline tst2029 & $07 / 12 / 99$ & 473 & 32.99 & 0.075 & 12 \\
\hline tst2030 & 07/13/99 & 474 & 33.87 & 0.43 & \\
\hline tst2031 & $07 / 13 / 99$ & 474 & 33.06 & 0.13 & 19 \\
\hline tst2032 & 07/14/99 & 475 & 33.43 & 0.71 & 1 \\
\hline tst2033 & 07/14/99 & 475 & 33.49 & 0.081 & 18 \\
\hline tst2034 & 07/15/99 & 476 & 33.77 & 0.85 & 1 \\
\hline tst2035 & $07 / 15 / 99$ & 476 & 32.92 & 0.052 & 124 \\
\hline tst2036 & $07 / 16 / 99$ & 477 & 32.93 & 0.90 & 1 \\
\hline tst2038 & 07/19/99 & 480 & 33.84 & 0.32 & 52 \\
\hline tst2039 & $07 / 19 / 99$ & 480 & 32.82 & 0.28 & 60 \\
\hline tst2040 & 07/20/99 & 481 & 34.13 & 0.12 & 121 \\
\hline tst2041 & $07 / 22 / 99$ & 483 & 34.24 & 0.48 & 40 \\
\hline tst2042 & 07/22/99 & 483 & 34.87 & 0.012 & 2000 \\
\hline tst2043 & $07 / 22 / 99$ & 483 & 34.83 & 0.006 & 6001 \\
\hline tst2044 & $07 / 22 / 99$ & 483 & 34.79 & 0.006 & 6501 \\
\hline tst2045 & 07/22/99 & 483 & 34.79 & 0.006 & 7501 \\
\hline tst2046 & 07/23/99 & 484 & 34.12 & 0.54 & 15 \\
\hline tst2047 & $07 / 23 / 99$ & 484 & 34.83 & 0.006 & 6001 \\
\hline tst2048 & $07 / 23 / 99$ & 484 & 34.00 & 0.040 & 217 \\
\hline tst2049 & $07 / 26 / 99$ & 487 & 31.47 & 0.34 & 59 \\
\hline tst2050 & $07 / 26 / 99$ & 487 & 34.34 & 0.006 & 9213 \\
\hline tst2051 & $07 / 26 / 99$ & 487 & 34.24 & 0.011 & 2156 \\
\hline tst2052 & 07/28/99 & 489 & 33.28 & 0.61 & 36 \\
\hline tst2053 & $07 / 28 / 99$ & 489 & 34.09 & 0.016 & 1001 \\
\hline tst2054 & 07/28/99 & 489 & 34.04 & 0.016 & 1000 \\
\hline
\end{tabular}




\begin{tabular}{|c|c|c|c|c|c|}
\hline $\begin{array}{c}\text { Run Number } \\
\text { tst2056 }\end{array}$ & $\begin{array}{c}\text { Date } \\
07 / 30 / 99\end{array}$ & $\begin{array}{l}\text { Day } \\
491\end{array}$ & $\begin{array}{r}\text { Pedestal } \\
36.03\end{array}$ & $\begin{array}{l}\text { Error } \\
0.008\end{array}$ & $\begin{array}{r}\text { Events } \\
770\end{array}$ \\
\hline tst2057 & $07 / 30 / 99$ & 491 & 35.76 & 0.068 & 66 \\
\hline tst2058 & $08 / 02 / 99$ & 494 & 35.94 & 0.26 & \\
\hline tst2059 & 08/02/99 & 494 & 40.52 & 0.024 & 100 \\
\hline tst2060 & 08/02/99 & 494 & 39.78 & 0.20 & \\
\hline tst2061 & $08 / 05 / 99$ & 497 & 36.32 & 0.31 & \\
\hline tst2062 & $08 / 05 / 99$ & 497 & 36.38 & 0.005 & 10000 \\
\hline tst2063 & $08 / 10 / 99$ & 502 & 35.68 & 0.30 & \\
\hline tst2064 & $08 / 10 / 99$ & 502 & 37.17 & 1.20 & \\
\hline tst2065 & $08 / 13 / 99$ & 505 & 35.87 & 0.37 & \\
\hline tst2066 & 08/16/99 & 508 & 35.29 & 0.54 & \\
\hline tst2068 & $08 / 17 / 99$ & 509 & 42.72 & 0.53 & \\
\hline tst2069 & $08 / 17 / 99$ & 509 & 39.48 & 0.010 & 2425 \\
\hline tst2071 & $08 / 19 / 99$ & 511 & 39.50 & 0.53 & \\
\hline tst2072 & $08 / 20 / 99$ & 512 & 42.66 & 0.68 & \\
\hline tst2073 & $08 / 23 / 99$ & 515 & 41.65 & 0.32 & \\
\hline tst2075 & $08 / 25 / 99$ & 517 & 36.65 & 0.65 & \\
\hline tst2076 & $08 / 27 / 99$ & 519 & 36.10 & 0.42 & \\
\hline tst2077 & $08 / 30 / 99$ & 522 & 35.07 & 0.35 & \\
\hline tst2078 & $08 / 31 / 99$ & 523 & 35.68 & 0.57 & \\
\hline tst2079 & 09/01/99 & 524 & 35.46 & 0.50 & \\
\hline tst2080 & $09 / 03 / 99$ & 526 & 35.81 & 0.57 & 27 \\
\hline tst2081 & $09 / 07 / 99$ & 530 & 35.60 & 0.30 & \\
\hline tst2082 & $09 / 08 / 99$ & 531 & 36.01 & 0.58 & \\
\hline tst2083 & 09/09/99 & 532 & 34.75 & 0.31 & \\
\hline tst2084 & $09 / 11 / 99$ & 534 & 35.68 & 0.54 & \\
\hline tst2085 & $09 / 14 / 99$ & 537 & 36.70 & 0.44 & \\
\hline tst2086 & 09/20/99 & 543 & 36.09 & 0.29 & 9 \\
\hline tst2087 & $09 / 22 / 99$ & 545 & 36.86 & 0.52 & \\
\hline tst2088 & $09 / 24 / 99$ & 547 & 36.13 & 0.45 & 39 \\
\hline tst2089 & $10 / 01 / 99$ & 554 & 36.30 & 0.26 & 118 \\
\hline tst2090 & $10 / 04 / 99$ & 557 & 36.60 & 0.45 & 47 \\
\hline tst2091 & $10 / 12 / 99$ & 565 & 36.46 & 0.26 & 13 \\
\hline tst2092 & $10 / 13 / 99$ & 566 & 36.31 & 0.75 & 1 \\
\hline tst2093 & $10 / 15 / 99$ & 568 & 36.83 & 0.59 & \\
\hline tst2094 & $10 / 15 / 99$ & 568 & 5.15 & 1.07 & \\
\hline tst2095 & $10 / 18 / 99$ & 571 & 7.88 & 0.36 & $\epsilon$ \\
\hline tst2096 & $10 / 21 / 99$ & 574 & 8.29 & 0.48 & 58 \\
\hline tst2097 & $10 / 26 / 99$ & 579 & 7.82 & 0.25 & 109 \\
\hline tst2098 & $10 / 29 / 99$ & 582 & 8.27 & 0.37 & \\
\hline tst2099 & $11 / 02 / 99$ & 586 & 8.16 & 0.33 & 7 \\
\hline tst2100 & $11 / 02 / 99$ & 586 & 43.00 & 1.49 & \\
\hline tst2101 & $11 / 02 / 99$ & 586 & 59.32 & 0.072 & 100 \\
\hline tst2102 & $11 / 02 / 99$ & 586 & 11.29 & 0.056 & 101 \\
\hline tst2103 & $11 / 09 / 99$ & 593 & 8.80 & 0.28 & 129 \\
\hline tst2104 & $11 / 12 / 99$ & 596 & 9.85 & 0.40 & 7 \\
\hline tst2105 & $11 / 16 / 99$ & 600 & 9.21 & 0.29 & 84 \\
\hline
\end{tabular}


Table 2.

Peak positions for data runs with the small tank between March, 1998 and November, 1999. The raw peak position and its uncertainty (Peak, Error), the peak width (Sigma), and the number of events in the fitted peak (N) are shown for both the EXCEL analysis and (for some runs) the alternate analysis. In the latter case, the true number of events is shown

- as Events. The peak, error, and sigma values are all in units of $\mathrm{pC}$.

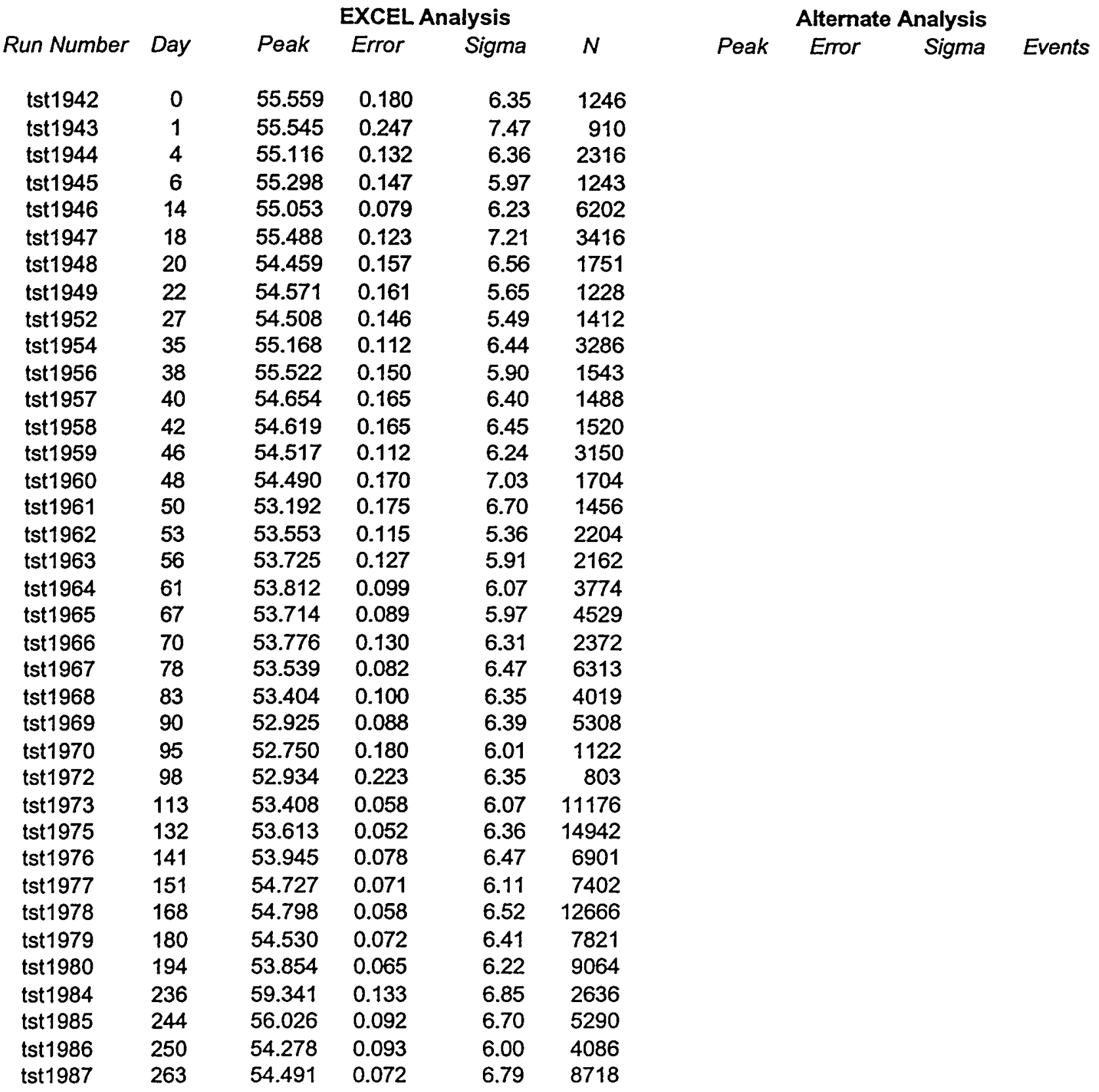

The tank was moved after this run. 


\begin{tabular}{|c|c|c|c|c|c|c|c|c|c|}
\hline \multirow[b]{2}{*}{$\begin{array}{c}\text { Run Number } \\
\text { tst1991 }\end{array}$} & \multirow[b]{2}{*}{$\begin{array}{c}\text { Day } \\
447\end{array}$} & \multicolumn{4}{|c|}{ EXCEL Analysis } & \multicolumn{4}{|c|}{ Alternate Analysis } \\
\hline & & $\begin{array}{c}\text { Peak } \\
105.383\end{array}$ & $\begin{array}{l}\text { Error } \\
0.273\end{array}$ & $\begin{array}{r}\text { Sigma } \\
6.98\end{array}$ & $N$ & Peak & Error & Sigma & Events \\
\hline tst1993 & 448 & 104.675 & 0.263 & 7.61 & & & & & \\
\hline tst2002 & 454 & 86.784 & 0.222 & 6.59 & & & & & \\
\hline tst2004 & 455 & 84.183 & 0.219 & 6.96 & & & & & \\
\hline tst2006 & 456 & 87.320 & 0.228 & 6.75 & & & & & \\
\hline tst2008 & 459 & 85.644 & 0.133 & 7.08 & 2830 & 85.269 & 0.143 & 7.75 & 2936 \\
\hline tst2010 & 460 & 88.695 & 0.195 & 5.86 & & & & & \\
\hline tst2013 & 461 & 87.927 & 0.564 & 6.30 & & & & & \\
\hline tst2015 & 462 & 83.180 & 0.245 & 6.03 & & & & & \\
\hline tst2017 & 463 & 84.662 & 0.228 & 6.96 & & & & & \\
\hline tst2019 & 467 & 83.474 & 0.103 & 6.13 & 3564 & 82.686 & 0.117 & 7.28 & 3905 \\
\hline tst2021 & 468 & 83.537 & 0.185 & 5.21 & & & & & \\
\hline tst2024 & 469 & 84.217 & 0.221 & 6.45 & & & & & \\
\hline tst2026 & 470 & 85.726 & 0.197 & 5.77 & & & & & \\
\hline tst2028 & 473 & 82.211 & 0.119 & 6.30 & 2848 & 81.311 & 0.130 & 7.13 & 3024 \\
\hline tst2030 & 474 & 84.481 & 0.199 & 6.00 & & & & & \\
\hline tst2032 & 475 & 82.901 & 0.205 & 5.93 & & & & & \\
\hline tst2034 & 476 & 83.414 & 0.225 & 6.63 & & & & & \\
\hline tst2036 & 477 & 81.981 & 0.194 & 5.57 & & & & & \\
\hline tst2038 & 480 & 83.466 & 0.126 & 6.73 & 2872 & 82.302 & 0.132 & 7.17 & 2951 \\
\hline tst2040 & 481 & 82.677 & 0.199 & 5.86 & 858 & 81.692 & 0.229 & 7.17 & 976 \\
\hline tst2041 & 483 & 82.489 & 0.140 & 6.05 & 1854 & 81.468 & 0.152 & 6.75 & 1960 \\
\hline tst2046 & 484 & 84.069 & 0.212 & 6.22 & & & & & \\
\hline tst2049 & 487 & 79.533 & 0.115 & 6.04 & 2778 & 78.905 & 0.126 & 6.86 & 2952 \\
\hline tst2052 & 489 & 79.708 & 0.126 & 5.26 & & & & & \\
\hline tst2058 & 494 & 83.731 & 0.115 & 5.94 & 2670 & 83.094 & 0.128 & 6.92 & 2897 \\
\hline tst2061 & 497 & 84.737 & 0.110 & 5.79 & & & & & \\
\hline tst2063 & 502 & 81.977 & 0.088 & 5.95 & 4546 & 81.105 & 0.095 & 6.59 & 4802 \\
\hline tst2065 & 505 & 82.416 & 0.106 & 5.44 & 2660 & 81.871 & 0.122 & 6.69 & 3016 \\
\hline tst2066 & 508 & 80.870 & 0.116 & 6.21 & & & & & \\
\hline tst2068 & 509 & 89.213 & 0.214 & 5.66 & & & & & \\
\hline tst2071 & 511 & 85.604 & 0.130 & 5.95 & & & & & \\
\hline tst2072 & 512 & 86.539 & 0.175 & 5.68 & & & & & \\
\hline tst2073 & 515 & 87.746 & 0.112 & 5.91 & 2782 & 86.494 & 0.120 & 6.51 & 2916 \\
\hline tst2075 & 517 & 81.555 & 0.238 & 6.80 & & & & & \\
\hline tst2076 & 519 & 81.114 & 0.130 & 5.85 & 2032 & 79.585 & 0.136 & 6.22 & 2080 \\
\hline tst2077 & 522 & 80.780 & 0.110 & 5.78 & 2768 & 79.682 & 0.120 & 6.45 & 2874 \\
\hline tst2078 & 523 & 80.778 & 0.161 & 6.08 & & & & & \\
\hline tst2079 & 524 & 81.119 & 0.177 & 5.75 & & & & & \\
\hline tst2080 & 526 & 80.673 & 0.133 & 6.02 & & & & & \\
\hline tst2081 & 530 & 80.198 & 0.102 & 6.03 & 3478 & 78.767 & 0.106 & 6.29 & 3537 \\
\hline tst2082 & 531 & 80.484 & 0.175 & 5.87 & 1112 & & & & \\
\hline tst2083 & 532 & 80.581 & 0.180 & 6.16 & 1166 & & & & \\
\hline tst2084 & 534 & 80.384 & 0.130 & 5.78 & 1960 & & & & \\
\hline tst2085 & 537 & 80.339 & 0.110 & 5.67 & 2641 & 79.017 & 0.118 & 6.12 & 2712 \\
\hline tst2086 & 543 & 79.893 & 0.076 & 5.84 & 5927 & 78.368 & 0.079 & 6.13 & 6034 \\
\hline tst2087 & 545 & 79.579 & 0.122 & 5.59 & 2096 & 78.220 & 0.131 & 6.10 & 2164 \\
\hline tst2088 & 547 & 79.548 & 0.139 & 6.08 & 1938 & 77.987 & 0.142 & 6.30 & 1960 \\
\hline tst2089 & 554 & 78.824 & 0.068 & 5.71 & 7146 & 77.418 & 0.071 & 6.07 & 7311 \\
\hline tst2090 & 557 & 78.551 & 0.106 & 5.62 & 2828 & 77.090 & 0.110 & 5.88 & 2879 \\
\hline
\end{tabular}


GAP2000-001

\begin{tabular}{cccccccccr} 
& \multicolumn{1}{c}{ EXCEL Analysis } & \multicolumn{3}{c}{ Alternate Analysis } \\
Run Number & Day & Peak & Error & Sigma & $N$ & Peak & Error & Sigma & Events \\
tst2091 & 565 & 77.370 & 0.062 & 5.49 & 7841 & 75.857 & 0.065 & 5.81 & 8009 \\
tst2092 & 566 & 77.514 & 0.165 & 5.58 & 1129 & & & & \\
tst2093 & 568 & 77.209 & 0.137 & 5.60 & 1946 & & & & \\
tst2094 & 568 & 48.811 & 0.327 & 5.67 & 300 & & & & \\
tst2095 & 571 & 46.476 & 0.105 & 5.44 & 2736 & 44.812 & 0.107 & 5.61 & 2773 \\
tst2096 & 574 & 46.196 & 0.095 & 5.41 & 3231 & 44.540 & 0.096 & 5.46 & 3256 \\
tst2097 & 579 & 46.027 & 0.075 & 5.29 & 5045 & 44.457 & 0.076 & 5.46 & 5108 \\
tst2098 & 582 & 45.026 & 0.095 & 4.96 & 2774 & 43.546 & 0.100 & 5.31 & 2842 \\
tst2099 & 586 & 44.110 & 0.078 & 4.93 & 4003 & 42.400 & 0.080 & 5.11 & 4063 \\
tst2100 & 586 & 80.205 & 0.412 & 5.14 & 156 & & & & \\
tst2103 & 593 & 44.464 & 0.061 & 4.93 & 6558 & 42.924 & 0.064 & 5.25 & 6710 \\
tst2104 & 596 & 43.537 & 0.090 & 4.90 & 3084 & & & & \\
tst2105 & 600 & 42.848 & 0.072 & 4.67 & 4188 & & & &
\end{tabular}

